\title{
Genomic Identifier
}

National Cancer Institute

\section{Source}

National Cancer Institute. Genomic Identifier. NCI Thesaurus. Code C45766.

One or more characters and/or numbers that are used to identify, name, or characterize the nature, properties, or contents of genomic sequences, mRNA transcripts, protein products, or other class of entities that occurs throughout the genome. 